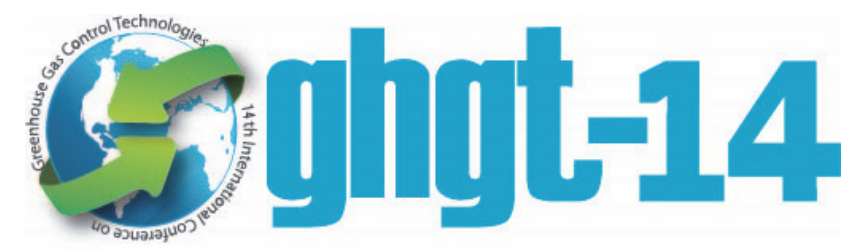

14th International Conference on Greenhouse Gas Control Technologies, GHGT-14

$21^{\text {st }}-25^{\text {th }}$ October 2018, Melbourne, Australia

\title{
Post-injection monitoring and well abandonment results of the Ketzin test site - an essential part for transfer of liability
}

\author{
Schmidt-Hattenberger, C. ${ }^{1}$, Jurczyk, A. ${ }^{1}$, Liebscher, A. ${ }^{2,3}$, Möller, F. ${ }^{1}$, Norden, B. ${ }^{1}$, \\ Prevedel, B..$^{2,4}$, Wiese, B. ${ }^{1}$, Zemke, K. ${ }^{2}$, Zimmer, M. ${ }^{1}$ \\ ${ }^{1}$ Helmholtz Centre Potsdam, GFZ German Research Centre for Geosciences, Telegrafenberg, 14473 Potsdam, Germany \\ ${ }^{2}$ Formerly GFZ Potsdam, Germany \\ ${ }^{3}$ Federal Office for the Safety of Nuclear Waste Management, 10117 Berlin, Germany \\ ${ }^{4}$ Federal Institute for Geosciences and Natural Resources, 30655 Hannover, Germany
}

\begin{abstract}
The Ketzin pilot site (Brandenburg, Germany) was the first European on-shore $\mathrm{CO}_{2}$ storage project and has successfully demonstrated the full life-cycle of a $\mathrm{CO}_{2}$ storage site, covering all phases and fulfilling all requirements defined by the EU CCS directive (European Commission 2011). After site assessment, characterization and development from 2004 to 2008, injection operation lasted from July 2008 to August 2013. During this period, about $67 \mathrm{kt} \mathrm{CO}_{2}$ were safely injected into an Upper Triassic sandstone reservoir. In September 2013 the site entered the post-closure/pre-transfer phase with final handover of the liability to the competent authority in 2018. Besides continuous post-injection monitoring and post-injection field experiments, main targets of the post-closure/pre-transfer phase were the backfilling and abandonment of the wells in compliance with regulatory requirements. This paper focusses on the post-injection well-integrity monitoring and the stepwise abandonment of the wells and closure of the site.
\end{abstract}

Keywords: $\mathrm{CO}_{2}$ storage; post-injection; legal and regulatory aspects; long term liability; abandonment

\section{Introduction}

The Ketzin site was the first European on-shore $\mathrm{CO}_{2}$ storage project, which included the two operational phases of a 5-years safe and reliable $\mathrm{CO}_{2}$ injection and subsequently a 4-years post-injection. Key attributes of the pilot site are (i) its location at the Ketzin-Roskow anticlinal structure in the North East German Basin (NEGB), (ii) a saline aquifertype storage reservoir at a depth of about $650 \mathrm{~m}$, consisting of sandstones of the Upper Triassic Stuttgart formation, (iii) a cap rock formed by a multilayer system of the Upper Triassic shales, and (iv) a number of 5 wells to be abandoned, i.e. four deep wells of about $750-800 \mathrm{~m}$ depth, and a shallower above zone observation well of $445 \mathrm{~m}$, which ends directly above the top of the multi-layered caprock. In the deep wells, various fibre-optic and multi-wire electrical measurement cables were built-in along the tubulars, originating from the applied downhole monitoring systems, as e.g. injection pressure sensor, distributed temperature sensing, thermal conductivity profiling by heatpulses, and permanent electrode arrays for resistivity tomography.

The Ketzin site itself is located in a rural area, as depicted in the aerial view of Figure 1. The cities Potsdam and Berlin are about $25 \mathrm{~km}$ apart, that means the storage site is not so far from urban areas, and therefore, had to undergo 
a strict permitting and monitoring procedure, regulated by the main operating plan issued by the mining authority of the Federal State of Brandenburg. This has been implemented in a multi-disciplinary monitoring concept which had been carried out during the whole injection life-cycle of the site [1, 2].

The $\mathrm{CO}_{2}$ storage reservoir of the site during and after the injection operation was characterized by a regular and stabilized $\mathrm{CO}_{2}$ plume evolution. In Figure 1, the time-lapse results derived from the corresponding 3D seismic data show schematically the $\mathrm{CO}_{2}$ gas phase at the reservoir. During the injection operation the area covered by the plume increases (Figure 1a to Figure 1b). Then, after the end of injection, the plume size starts to decrease or shrink, probably due to the onset of dissolution of $\mathrm{CO}_{2}$ into the formation fluid (Figure 1b to Figure 1c) [3]. In addition, the seismic time lapse data show no variation outside the storage complex, and therefore, no hints to any type of $\mathrm{CO}_{2}$ leakage out of the reservoir exist. Although the size between the modelled and imaged plume differs, in general there is a good conformance between the modelling and the seismic monitoring data, and the above mentioned post-injection plume shrinkage indicates onset of $\mathrm{CO}_{2}$ solubility trapping, and therefore, also evolution towards long-term stability [4].

The Ketzin site has now completed the full life-cycle of a storage site as defined in the guidance document to the EU directive [5]. The injection operation itself was permitted under the German mining law. For the abandonment phase, the directive "Richtlinie des Oberbergamtes in Clausthal Zellerfeld" is binding. This directive is a mandatory regulatory requirement, and has to be carried out for wells to be abandoned in Germany.

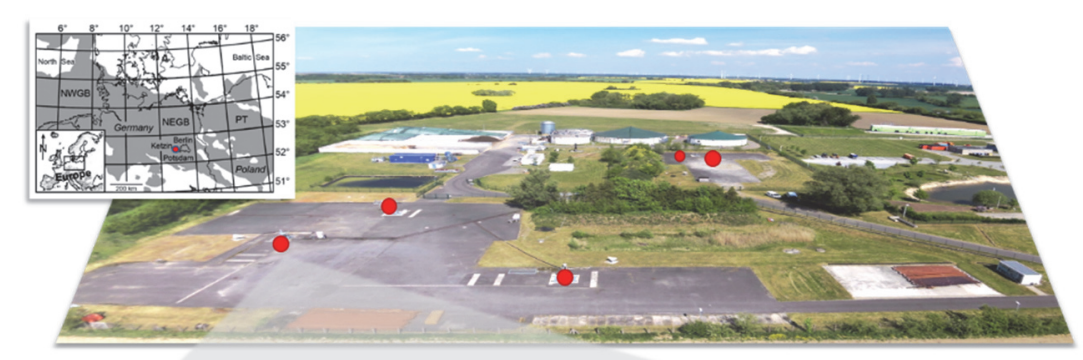

(a)

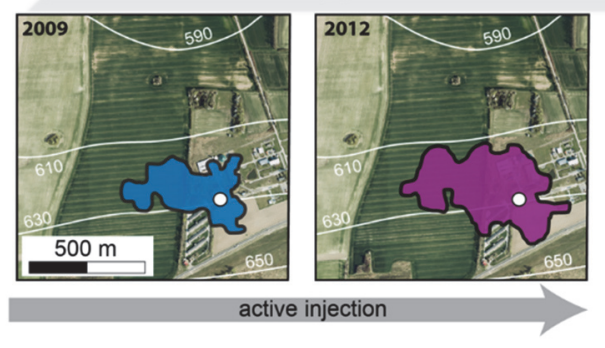

(c)

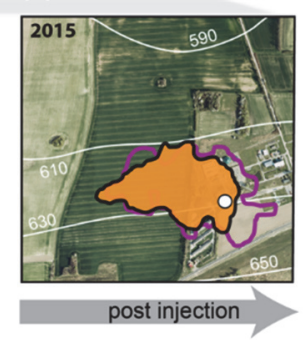

Fig. 1. Location of $\mathrm{CO}_{2}$ plume at the Ketzin pilot site during the active and post injection phase. The upper panel shows an aerial view of the site (Photo: GFZ), located in the NEGB (inlay left corner), and the wellbores are indicated by red dots. In the lower panel, the signature of the free (gaseous) $\mathrm{CO}_{2}$ is derived from the corresponding 3D seismic surveys [3] and schematically drawn at (a) $\sim 22,000 \mathrm{t} \mathrm{CO},,(\mathrm{b}) \sim 61,000 \mathrm{t} \mathrm{CO}{ }_{2}$ and (c) $\sim 67,000$ t $\mathrm{CO}_{2}$,. The white dot indicates the injection well Ktzi 201.

Due to the given regulations, the requirements for well integrity surveys have been fulfilled from the early beginning of the Ketzin project, i.e. already during the injection phase, to guarantee operational safety and dedicate highest priority to the protection of humans and environment. A specific stipulation by the mining authority was the observation of cementation integrity in the annuli between technical and monitoring casing of the individual wellbores. In general, as standard procedure, cement bond $\operatorname{logs}(\mathrm{CBL})$ are the method of choice to evaluate and control the stability and safety of the wells. At Ketzin, the CBL baseline was measured already in 2007, after drilling and completion of the wells, and further regular repeats were conducted in the following years. During the progressing 
injection, the fluid in the wellbores has been displaced by injected $\mathrm{CO}_{2}$, and therefore, the water level in all wells decreased towards the sandstone reservoir zone at 625 to $650 \mathrm{~m}$ depth and below. As a consequence, the CBL logging was no longer possible. In order to meet the regulatory requirements for the well integrity and to provide data for the post-injection phase, an alternative monitoring program was set up composed of three complementary methods:

- Pulsed neutron gamma logs (PNG) to determine $\mathrm{CO}_{2}$ saturation along the wellbore

- Magneto-induction defectoscopy (MID) as wellbore casing diagnostic

- Video camera inspections for screening the inner surface of the casing

As displayed in Figure 2, the post-injection measurements comprise an extensive data archive of almost four years, and therefore, strengthened the reliability of the evaluations which had to been provided prior to the technical and legal closure procedures.

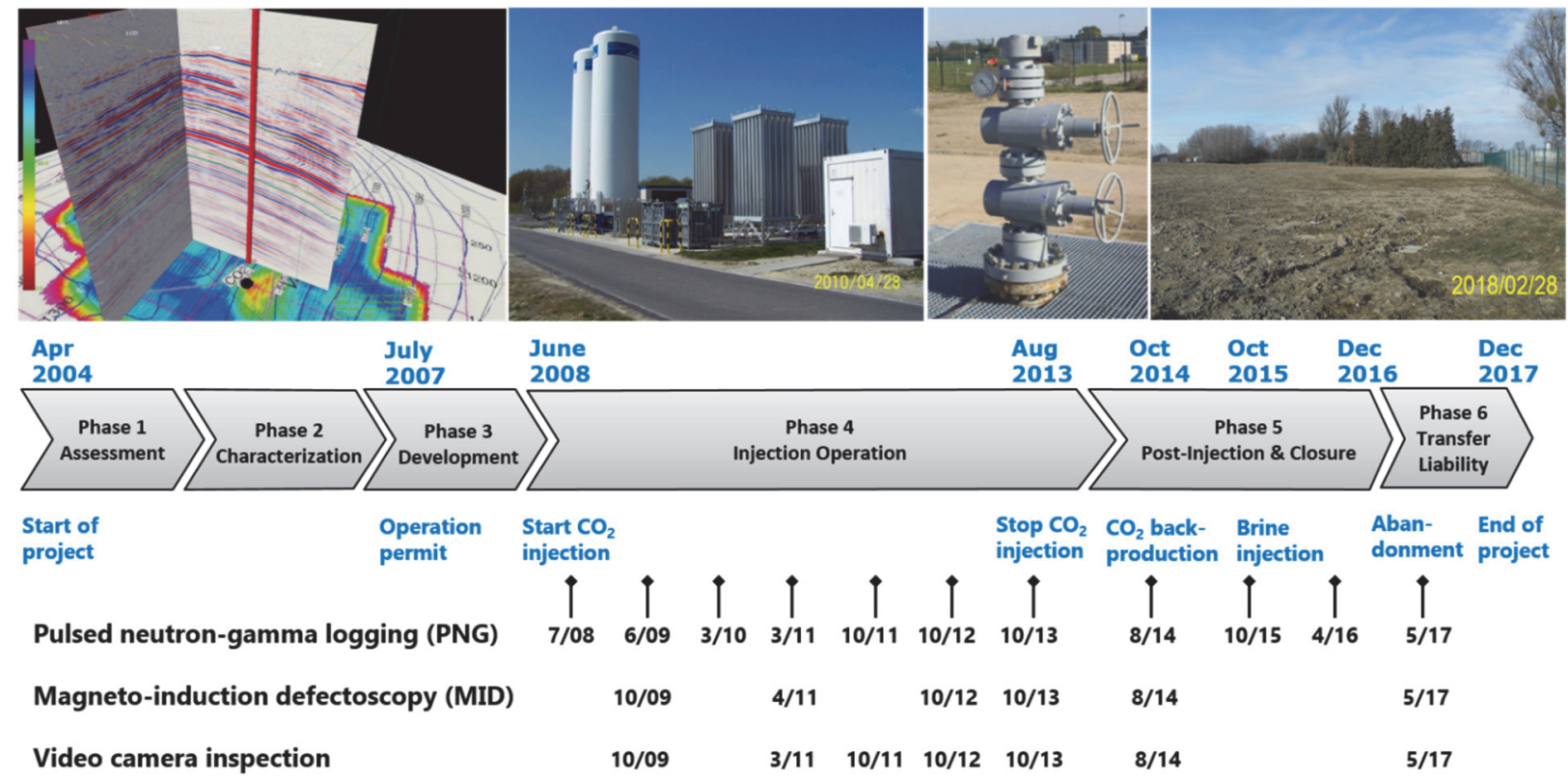

Fig. 2. Completed life-cycle of the Ketzin $\mathrm{CO}_{2}$ storage site with the relevant campaigns for well-integrity monitoring (month/year), continuing until the post-injection phase (Photos: GFZ)

\section{Post-injection well-integrity monitoring}

After the end of the $\mathrm{CO}_{2}$ injection in 2013, the well integrity monitoring continued until the start of the well abandonment in summer 2017. The alternative well integrity monitoring program for the gas-filled Ketzin wellbores comprising PNG, MID and video inspection, was approved by the mining authority.

\section{Pulsed neutron-gamma logging (PNG)}

The physical principle is based on the thermal decay time and subsequent the capture rate of thermal neutrons in the borehole and the formation after exposure by a burst of high-energy neutrons. The capture rate depends primarily on the presence of choride ions and secondarily on water saturation and therefore indirectly allows to determine the presence of gas. The typical penetration depth is $\sim 50 \mathrm{~cm}$ into the formation, i.e. the near-wellbore area. In Figure 3 , the baseline and all PNG repeats are assembled, together with the lithology and the completion of the well Ktzi 200. 
To derive the $\mathrm{CO}_{2}$ saturation from the capture rate (Sigma. $\mathrm{CU}$ ), a proven conventional displacement saturation model from Baumann et al. (2014) has been applied. The completion scheme (Figure 3) shows the $12 \mathrm{~m}$ long casing segments and the upper filter screen at $\sim 642-651 \mathrm{~m}$, providing a hydraulic connection to the sandstone reservoir located at a depth of 635-650 m. The different PNG logs of Figure 3 indicate in particular the saturation changes within the reservoir as a response to varying injection rates and $\mathrm{CO}_{2}$ buyoancy. The reservoir target zone shows decreasing $\mathrm{CO}_{2}$

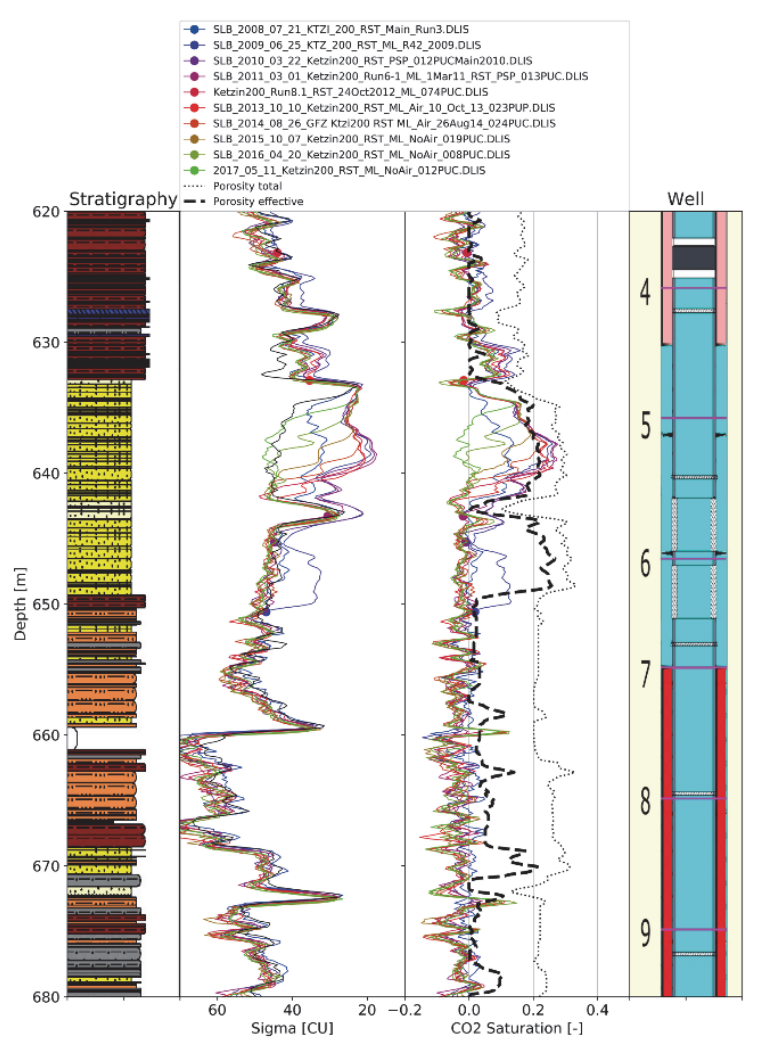
saturation in the post-injection phase reflecting progressive $\mathrm{CO}_{2}$ dissolution in formation brine and subsequent reduction of plume thickness (clearly visible in the curves of the 2015, 2016 and 2017 repeat). The lime-green curve displays the logging result of 2017, where a strongly decreased saturation is seen. Only directly below the caprock, a weak saturation signal is visible, due to the buoyant $\mathrm{CO}_{2}$. For the caprock and overburden region, which is only partially shown here, no changes between time-lapse measurements and baseline were observed. Due to the sufficient to good bonding of the cementation in the annulus between monitoring and technical casing at Ktzi 200, consistent boundary conditions existed for the data processing.

Fig. 3. PNG data from 10 selected surveys of Ktzi 200, drawn as Sigma in capture units $(\mathrm{CU})$ and processed as $\mathrm{CO}_{2}$ saturation. The lithology is given on the left side, the well completion scheme on the right side, where the numbers indicate electrodes of the permanent geoelectric array.

\section{Magneto-induction defectoscopy (MID)}

The MID surveys were conducted in cooperation with VNG Gasspeicher GmbH (VGS) and Gazpromenergiadiagnostika LCC (GED) on a regular basis. The MID is a logging device, which uses the technique of electromagnetic (EM) non-destructive material testing (Figure 4). A highpower generator coil produces pulse sequences of different duration time which can penetrate multiple tubulars and magnetize the metal casing. The corresponding magnetization intensity and its decay along the tubing sections is measured by receiver coils as a complex time domain profile [7, 8]. The recorded data depend on the thickness and diameter of the casing pipe, and the electrical resistivity of the casing material. All metal components of the well completion, as e.g. casing shoes, collars, packers and downhole electrodes, can be identified as increase in signal amplitude relative to the nominal wall thickness of the casing. A decrease in the signal amplitude relative to the nominal wall thickness would indicate a loss of material by scratches and pinholes, which might potentially refer to corrosion.

Fig. 4. MID logging tool under preparation for the last measurement campaign in May 2017 (Photo: GFZ).

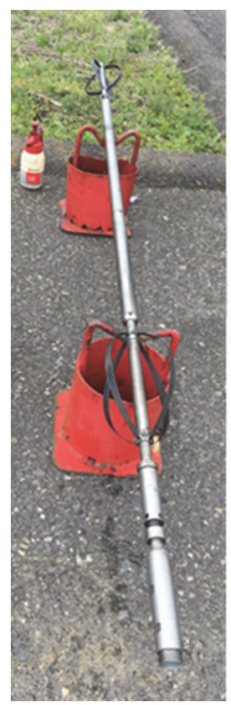


In Figure 5, a section from a MID log is presented for (i) a short delay time Z10 (10 ms) which corresponds to the inner $5^{1 / 2 "}$ monitoring casing (nominal wall thickness: $9.17 \mathrm{~mm}$ ), and (ii) a long delay time Z30 (30 ms) which corresponds to the outer $9^{5 / 8}$ technical casing (nominal wall thickness: $8.94 \mathrm{~mm}$ ). The MID processing results are based on the magnetic response pattern of the average casing wall thicknesses (in $\mathrm{mm}$ ) and presented for the interval between 2014 and 2017, depicted in the right panel of Figure 5. For the two casings under investigation, the data show no temporal changes in casing thicknesses and the determined spatial wall thickness variations are below $0.45 \mathrm{~mm}$ which is within the tubing's manufacturing tolerance $(\sim 5 \%)$. It should be noted that this technique presents a kind of volumetric monitoring, and therefore, corrosion is determined as volumetric loss of material, which may not be linearly correlated to minimum wall thickness due to pitting or cracks. To get more detailed information on small scale corrosion of the inner casing surface, regular video camera inspections confirmed and complemented the results of the MID logging.

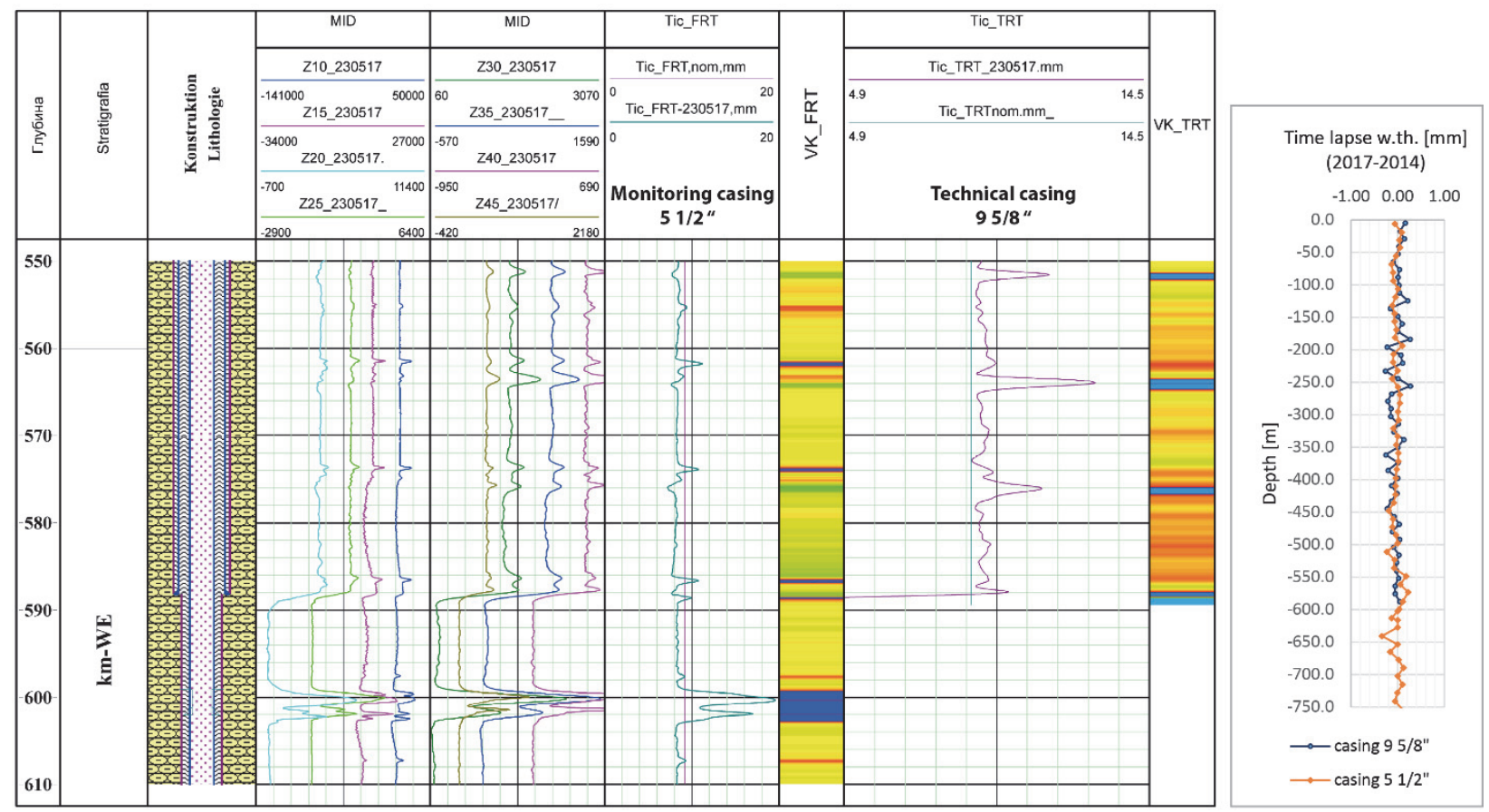

Fig. 5. Section of a MID log, measured at Ktzi 200. The left panel shows results of the MID response for the monitoring (5 ${ }^{1 / 2 ")}$ and the technical casing $\left(9^{5 / 8}\right.$ "), the color-coded defectograms indicate qualitatively the mass of metal (e.g. casing shoe of $9^{5 / 8 "}$ pipe at 588 m, first filter screen section of $5^{1 / 2 "}$ pipe at $\sim 642-651 \mathrm{~m}$, and regular pipe connections). The small panel on the right side presents the residual of the wall thickness, derived from the logs of 2017 and 2014.

\section{Video inspection}

From the last logging campaign in May 2017, a video example from the well Ktzi 200 is shown in Figure 6. While the video inspections from all wells image weak scratches on the inner casing surfaces due to the regular deployment of downhole logging tools, they hardly show pitting or surface corrosion of the casings on the macroscopic scale. This is in good coincidence with investigations of in-situ samples from cut casing material retrieved during the 


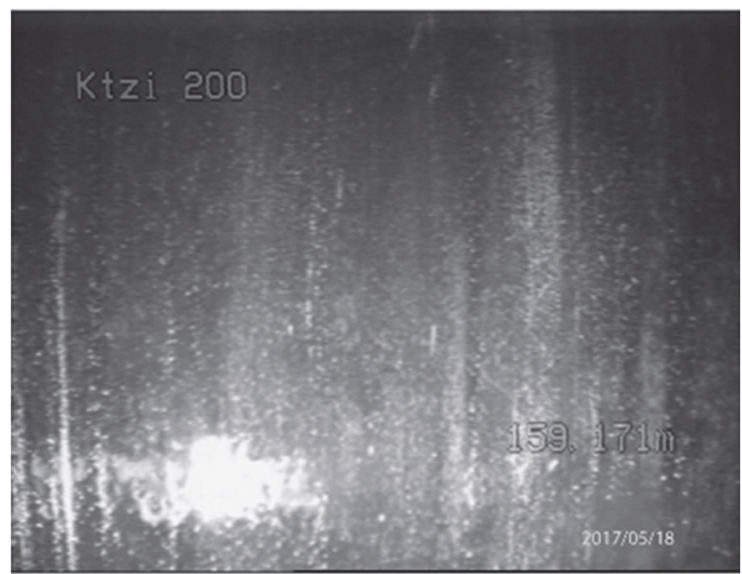

abandonment of well Ktzi 200, Ktzi 201 [9] and Ktzi 202 [10]. Effects of slight surface erosion can be seen on the microscopic scale and have been assessed as not compromising the overall casing integrity [9].

Fig. 7. Result from the video camera inspection at Ktzi 200. The inner casing surface shows scratches from the regular logging tool operations (Photo: GFZ).

\section{Step-wise well abandonment approach}

Being the first $\mathrm{CO}_{2}$ storage site to be abandoned, a two-stage abandonment strategy - guided by the national mandatory regulation "Richtlinie des Oberbergamtes in Clausthal Zellerfeld über das Verfüllen auflässiger Bohrungen" - has been negotiated and agreed with the mining authority. This regulation was first applied and feasibility tested to well Ktzi 202. In 2013, the reservoir and caprock section of well Ktzi 202 were plugged with $\mathrm{CO}_{2-}$ resistant "EverCRETE" cement. A gas-membrane-and-pressure-sensor system monitored this cement plug for its gas tightness over two years. No gas increase or pressure changes have been detected [11]. The uppermost $3 \mathrm{~m}$ of the cement plug were cored in summer 2015 and their petrophysical properties analyzed [10]. After proving the integrity

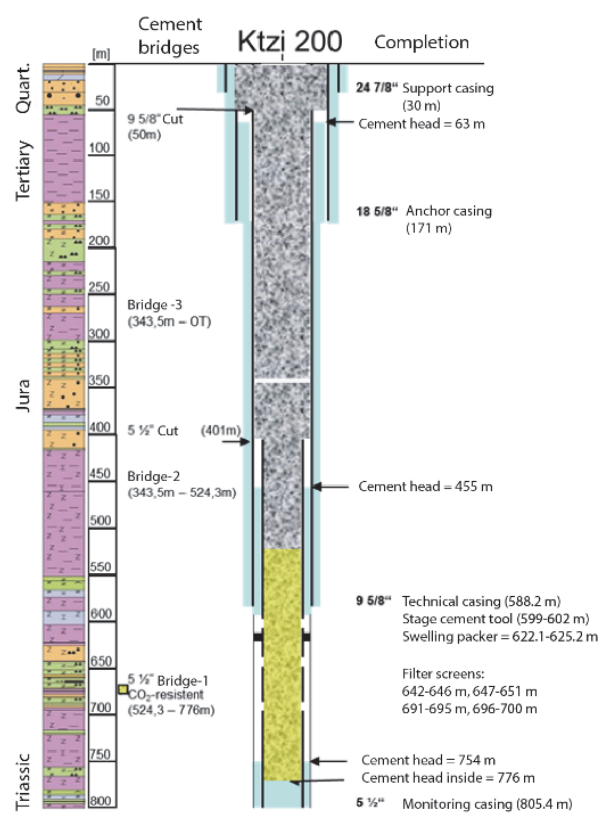
of this cement plug, well Ktzi 202 was finally abandoned by successivly cutting the casings at their respective cement heads and backfilling the remaining part of the well with standard class $\mathrm{G}$ cement. This two-cement abandonment approach with $\mathrm{CO}_{2}$-resistant "EverCRETE" and standard class $\mathrm{G}$ cement was then applied to the remaining three deep wells Ktzi 200, Ktzi 201 and Ktzi 203. The final abandonment of these wells took place in 2017. For example, the operational time necessary for completion of the cement job of the well Ktzi 200 was 12 days.
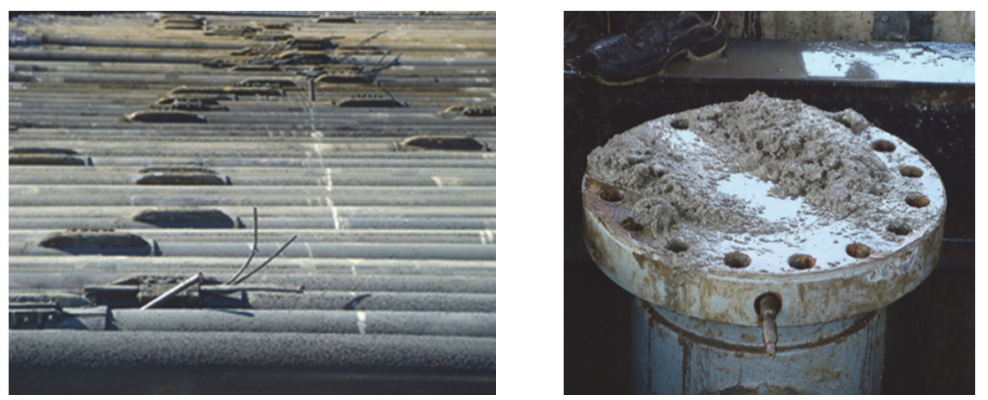

Fig. 8. Completion scheme for Ktzi 200 according a two-cementation concept consisting of $\mathrm{CO}_{2}$ resistant "Evercrete" and standard class $\mathrm{G}$ cement (left side), dismantling of the monitoring casing with centralizers and cables (centre), cementation of Ktzi 200 above-ground (right side), (Photos: GFZ). 


\section{Sidetrack drilling prior to abandonment}

The well completion of Ktzi 203 with glassfibre reinforced pipes allowed for sidetrack drilling. Two side-tracks covering the lower part of the cap rock and also the entire reservoir section (Figure 9, left) have been drilled and cored prior to cementation. The retrieved cores (Figure 9, right) have been in contact with the stored $\mathrm{CO}_{2}$ for more than nine years and provide a unique sample set to study $\mathrm{CO}_{2}$ triggered changes in petrophysical and mineralogical reservoir properties. Further studies on these geochemical alterations are still in progress. First results from monitoring of the gas composition and stable carbon isotopes are discussed in [12].
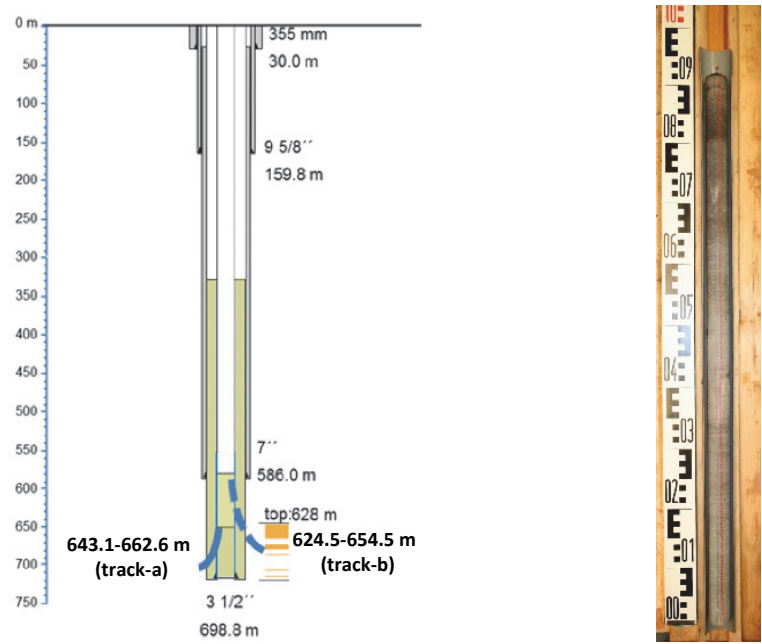

Fig. 9. Schematic of the sidetrack drilling in the well Ktzi 203 (left side), core sample Ktzi_203b_section_14-1b (right side, Photo: GFZ).
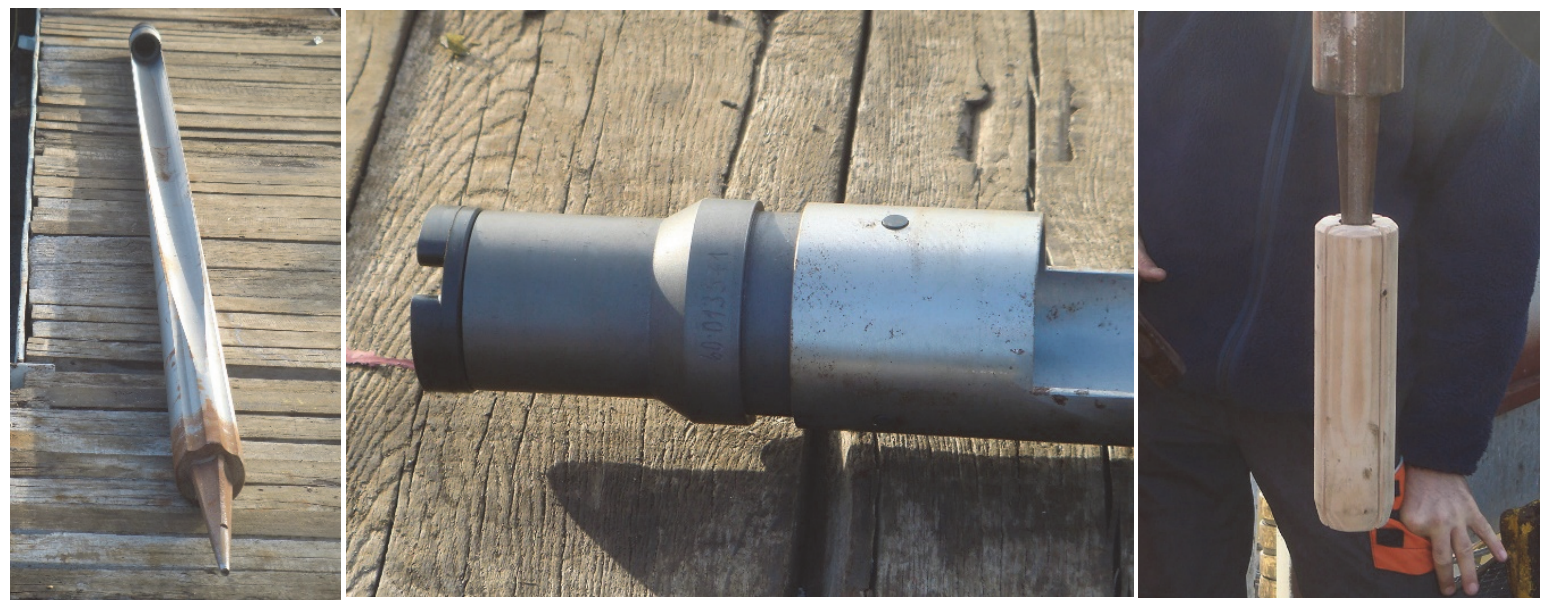

Fig.10. Components used for the sidetrack drilling: whip stock (left), technical detail of the applied mechanical setting tool (centre), wood plug as base of the whip stock (right) (Photos: GFZ). 


\section{Conclusions}

- The combined well integrity monitoring program with PNG, MID and video inspection has been proven as suitable alternative for CBL logging in gas-filled wellbores.

- The $\mathrm{CO}_{2}$-resistant "EverCRETE" cement zone tested at the bottom of well Ktzi 202 behaved stable and gas-tight over two years of monitoring.

- The two-cement well completion test exercised at well Ktzi 202 was approved by the German mining authority as suitable abandonment procedure for $\mathrm{CO}_{2}$ wells.

- Successful post-injection monitoring and well abandonment, fulfilling the high-level criteria of the EU CCS Directive and national regulations, enabled transfer of liability, closed the life-cycle of the Ketzin pilot site and provides a benchmark for future $\mathrm{CO}_{2}$ storage sites.

\section{Acknowledgements}

The authors gratefully acknowledge the funding for the Ketzin project received from the European Commission ( $6^{\text {th }}$ and $7^{\text {th }}$ Framework Program), two German ministries - the Federal Ministry of Economic Affairs and Energy and the Federal Ministry of Education and Research - and numerous industry partners since 2004. The above presented R\&D activities are funded within the project COMPLETE by the Federal Ministry of Education and Research. Further funding is received by VGS, RWE, Vattenfall, Statoil, OMV and the Norwegian CLIMIT program.

\section{References}

[1] Martens S, Conze R, De Lucia M, Henninges J, Kempka T, Liebscher A, Lüth L, Möller F, Norden B, Prevedel B, Schmidt-Hattenberger C,

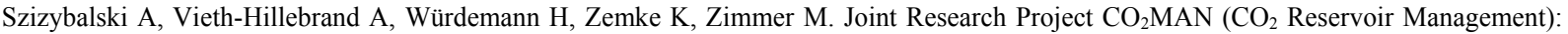
Continuation of Research and Development Work for $\mathrm{CO}_{2}$ Storage at the Ketzin Pilot Site. In: Liebscher A, Münch U, editors. Geological Storage of $\mathrm{CO}_{2}$ - Long Term Security Aspects, Advanced Technologies in Earth Sciences. Springer International Publishing Switzerland; 2015. p. 1-32.

[2]Bergmann P, Diersch M, Götz J, Ivandic M, Ivanova A, Juhlin C, Kummerow J, Liebscher A, Lueth S, Meekes S, Norden B, SchmidtHattenberger C, Wagner F, Zhang F. Review on geophysical monitoring of $\mathrm{CO}_{2}$ injection at Ketzin, Germany. Journal of Petroleum Science and Engineering 2016; 139:112-136.

[3] Huang F, Bergmann P, Juhlin C, et al. The First Post-injection Seismic Monitor Survey at the Ketzin Pilot $\mathrm{CO}_{2}$ Storage Site: Results from Timelapse Analysis. Geophysical Prospecting 2018; 66:62-84.

[4] Lüth S, Ivanova A, Kempka T. Conformity assessment of monitoring and simulation of $\mathrm{CO}_{2}$ storage: A case study from the Ketzin pilot site. International Journal of Greenhouse Gas Control 2015; 329-339.

[5] European Commission. Implementation of Directive 2009/31/EC on the Geological Storage of Carbon Dioxide - Guidance Document 1 Criteria for Transfer of Responsibility to the Competent Authority; 2011.

[6] Baumann G, Henninges J, De Lucia M. Monitoring of saturation changes and salt precipitation during $\mathrm{CO}_{2}$ injection using pulsed neutrongamma logging at the Ketzin site. Intl J Greenhouse Gas Control 2014; 28:134-146.

[7] Ansari A, Ziad Libdi A, Naeem K, Aslanyan A, Aslanyan I, Volkov M, Arbuzov A, Achkeev A, Shnaib F, Makhiyanov R. Triple-Barrier Thickness Scanning Using Through-Tubing Pulse-Magnetic Logging Tool. SPE-176655-MS, SPE Russian Petroleum Technology Conference, 26-28 October 2015, Moscow, Russia.

[8] Zemke K, Liebscher A, Möller F. Monitoring of well integrity by magnetic imaging defectoscopy (MID) at the Ketzin pilot site, Germany. Energy Procedia 2017; 125:535-542.

[9] Gawel K, Todorovic J, Liebscher A, Wiese B, Möller F, Opedal N. Study of casings retrieved from the final abandonment of the Ketzin pilot site. $14^{\text {th }}$ International Conference on Greenhouse Gas Control Technologies, GHGT-14, 21-25 October 2018, Melbourne, Australia.

[10] Gawel K, Todorovic J, Liebscher A, Wiese B, Opedal N. Study of materials retrieved from Ketzin well. Energy Procedia (2017); 114:57995815.

[11] Prevedel B, Martens S, Norden B, Henninges J, Freifeld BM. Drilling and abandonment preparation of $\mathrm{CO}_{2}$ storage wells - Experience from the Ketzin pilot site. Energy Procedia 2014; 63:6067-6078.

[12] Zimmer M, Szizybalski A, Norden B, Vieth-Hillebrand A, Liebscher A, and the Ketzin group. Monitoring of the gas composition and stable carbon isotopes during side track drilling in Ktzi 203 at the Ketzin $\mathrm{CO}_{2}$ storage pilot site, Germany. Advances in Geosciences 2018; 45:7-11. 